\title{
Editorial
}

\section{Open Access, the Creative Commons Attribution Licence, and the Nutrition Society journals*}

(First published online 25 October 2012)

\section{Open Access}

Increasing numbers of research funders, including the Wellcome Trust, Research Councils UK, and the National Institutes of Health, require that articles published from the work that they fund are "Open Access", meaning that they are made available to all readers without those readers needing to pay a subscription to the journal or a fee to gain access to the article. In the Open Access model of scientific publishing, the costs of publication are borne through a one-off payment from the author's funding body or institution. Open Access publication has been available in both the British Journal of Nutrition and Public Health Nutrition for some time, although only a minority of articles published in these two journals are Open Access. Many of the authors who publish in the BJN and $P H N$ are not required by their funders to adopt Open Access and many do not have access to the funds to do so voluntarily. Therefore, we continue to offer publication in the $B J N$ and $P H N$ through the traditional model. However, because we understand that Open Access is appealing to some authors, in collaboration with Cambridge University Press, the Nutrition Society recently launched a fully Open Access journal, Journal of Nutritional Science $^{(1,2)}$. However, it is also worth noting that, for over 12 years, the Nutrition Society has made the content of the BJN and $P H N$ available for free to all users after 12 months.

\section{Immediacy of availability of accepted papers}

The ability to display and access articles electronically means it is now possible to make them available to readers prior to their publication in final form. For both the $B J N$ and $P H N$, the final "Version of Record" of each accepted article is made available to subscribers, or in the case of an Open Access article, to all users, as soon as it is ready and before it is assigned to a specific issue of the journal. At this stage, the article is listed on PubMed and may be identified by searches, read and cited. This is a tremendous advantage to both authors and readers, because it means that the content of the article becomes available some time in advance of publication of the final version of the article. In fact, all that is missing from this final Version of Record is the volume and final page numbers of the article. Both the Version of Record and the final published version of the article share the same digital object identifier ("doi number") which is unique to each publication and aids citation of an article before its volume and page numbers are known. In parallel with their requirement for Open Access, some funders require that articles featuring work they have funded become freely available "at the time of publication". For the BJN and $P H N$, the time of publication is interpreted to be when the final Version of Record is made available on-line.

\section{Copyright, Licence to Publish and the Creative Commons Attribution Licence}

Many journals require transfer of copyright of the content of the articles they publish from the author to a publisher or to an academic society. The Nutrition Society ceased using this model in its journals many years ago, with the introduction, in place of copyright transfer, of "licence to publish". Under licence to publish, authors grant the Nutrition Society the exclusive right to publish the article and to reproduce and distribute it. Authors (or their institution) retain copyright. Many authors do not realise this, even though they have signed the licence to publish form, and even fewer probably know their rights under licence to publish. To quote from the form signed by authors: "You retain the right to use your own article (provided you acknowledge the published original in standard bibliographic citation form) as follows: for the internal educational or other purposes of your own institution or organisation; mounted on your own or your institution's website; posted to free public servers of preprints and/or articles in your subject area; in whole or in part, as the basis for your own further publications or spoken presentations, although ideally not before 6 months have elapsed after publication". Even under licence to publish, anyone who does not own copyright (i.e., normally anyone other than the authors) is required to request permission to use any of the content of a published article, for example in a presentation or in another publication, and the original source must be clearly and appropriately cited. In parallel with their requirement for 
Open Access, some funders require that articles featuring work they have funded be placed in one or more repositories from where they can be accessed electronically free of charge by any user. Licence to publish permits this for all articles published in the $B J N$ or $P H N$, whether they are Open Access or not.

The basis of Open Access is the view that the full benefit of a scientific publication cannot be realised if there are restrictions to access to that publication. This view is now being extended beyond access, to re-use of the content of publications. To enable re-use of content a new licencing scheme is being adopted. This is termed the "Creative Commons Attribution Licence". This licence permits others to copy, distribute and display the work and to adapt it, so long as attribution is given to the original author and copyright holder. This attribution should be in the manner specified by the author or copyright holder. Two forms of this licence either restrict further commercial reuse ${ }^{(3)}$ or allow others to make commercial reuse of the work ${ }^{(4)}$. In parallel with their requirement for Open Access and for placing articles in one or more freely-accessible repositories, some funders require, or will soon require, that articles featuring work they have funded be published under the more permissive licence. Currently articles published in the BJN and $P H N$ under Open Access are subject to the conditions of the so-called "Creative Commons Attribution-NonCommercial-ShareAlike Licence" (3). This licence permits others to copy, distribute and display the work and to adapt it, so long as attribution is given to the original author and copyright holder, but does not permit commercial reuse of the work. Along with the publishers of the $B J N$ and $P H N$, the Nutrition Society is currently exploring the full implications of adopting the more permissive licence. The more permissive version of the Creative Commons Attribution Licence ${ }^{(4)}$ could allow uncontrolled spreading and less serious use and interpretation of scientifically published matter. The protection of authors, institutions and funders against other entities' use of their work is much diminished by this licence. Whilst we fully support wide dissemination and freedom of access to the science published in the BJN and $P H N$, we also think it is of great importance that publishers, research funding agencies and authors carefully investigate and consider the full implications of any threat to scientific rigour and to the integrity of authors any new schemes for publishing and "article ownership" might pose.

\section{Summary and conclusions}

The conditions of publishing are changing with electronic advances creating both opportunities and challenges for funders, authors, readers, academic societies, institutions, librarians and publishers. Open Access is a revolution in the way that articles are published and made available to stakeholders. Funders are increasingly requiring that articles featuring research that they have supported be published according to the Open Access model, be placed in repositories that are freely accessible, and be subject to a Creative Commons Attribution Licence. Both the BJN and $P H N$ have offered Open Access publication for some time, all publications in both journals are freely available to all users after 12 months, and JNS is fully Open Access. Articles published under Open Access in the BJN, PHN and JNS are subject to a form of Creative Commons Attribution Licence that permits others to copy, distribute and display the work and to adapt it, so long as attribution is given to the original author. Obviously this licence permits authors to place the Version of Record of their article in repositories. Authors of nonOpen Access articles published in the BJN or PHN retain copyright under Licence to Publish, and this allows them to place the Version of Record of their article in repositories, although an embargo period of 6 months is suggested. At the current time authors meet requirements of funders by publishing in the BJN, PHN or JNS.

Philip C. Calder Editor-in-Chief, British Journal of Nutrition Human Development and Health Academic Unit Faculty of Medicine University of Southampton Southampton $U K$

Email pcc@soton.ac.uk

Agneta Yngve Editor-in-Chief, Public Health Nutrition Department of Health, Nutrition and Management Faculty of Health Sciences Oslo and Akershus University College of Applied Sciences Oslo

Norway

Email agneta.yngve@hioa.no

doi:10.1017/S0007114512004928

\section{References}

1. Calder PC (2012) BJN gets a new sister! Br J Nutr 107, 1561.

2. Calder PC (2012) The Nutrition Society fully engages with the Open Access model of publishing: Journal of Nutrition Science. J Nutr Sci 1, e1.

3. http://creativecommons.org/licenses/by-nc-sa/2.5/ (accessed 20 September 2012).

4. http://creativecommons.org/licenses/by/2.0/uk/ (accessed 20 September 2012). 